\title{
Colorectal cancer and the blood loss paradox
}

Orouba Almilaji MSc ${ }^{12}$, Sally D Parry MD FRCP ${ }^{1}$, Sharon Docherty PhD ${ }^{2}$, Jonathon Snook MA DPhil FRCP 1

${ }^{1}$ Gastroenterology Unit, Poole Hospital, University Hospitals Dorset, Poole, UK

${ }^{2}$ Department of Medical Science and Public Health, Bournemouth University, Bournemouth, UK

Correspondence: $\quad$ Dr Jonathon Snook

Consultant Gastroenterologist

Poole Hospital, UHD

Longfleet Road, Poole

Dorset BH15 2JB

Tel : 00443000198678

E-mail : Jonathon.Snook@gmail.com 


\section{Abstract}

\section{Background}

Faecal occult blood (FOB) positivity and iron deficiency anaemia (IDA) are common manifestations of colorectal cancer (CRC) and both potentially facilitate diagnosis at an earlier, more treatable stage. It has been assumed that both are the consequence of low-grade blood loss from the tumour bed.

\section{Method}

A retrospective analysis of 1121 cases of $\mathrm{CRC}$ diagnosed at a single centre between 2010 and 2016, comparing cases presenting via FOB-based bowel cancer screening programme (BCSP) and IDA pathways for a series of variables including age, sex, tumour location and prevalence of anaemia.

\section{Results}

The BCSP and IDA pathways each accounted for about $15 \%$ of the total case load. There were significant differences between the BCSP and IDA subgroups in median age (68 $\vee 78$ years : $\mathrm{P}<0.001)$, median $\mathrm{Hb}(138 \vee 89 \mathrm{~g} / \mathrm{l}$ : $\mathrm{P}<0.001)$ and proportion of lesions in right colon $(31.1 \% \vee 82.5 \%: \mathrm{P}<0.001)$. The major disparity in the prevalence of anaemia (overall $20.0 \% \vee 98.2 \%$ : $\mathrm{P}<0.001)$ persisted when controlled for tumour location.

\section{Conclusion}

Paradoxically, CRC screening through the detection of FOB positivity and IDA identifies distinctly different sub-populations of cases. The theoretical implication is that an additional mechanism may be required to explain the development of IDA in CRC. The practical implication is that screening for IDA may have a complementary role to the BCSP in population screening for CRC. 


\section{Summary box}

\begin{tabular}{|l|l|}
\hline $\begin{array}{l}\text { What is already known } \\
\text { about this subject? }\end{array}$ & $\begin{array}{l}\text { Faecal occult blood (FOB) positivity and iron deficiency } \\
\text { anaemia (IDA) are common early manifestations of } \\
\text { colorectal cancer (CRC), presumed due to low-grade } \\
\text { blood loss from the tumour bed. }\end{array}$ \\
\hline $\begin{array}{l}\text { What are the new } \\
\text { findings? }\end{array}$ & $\begin{array}{l}\text { Patients with CRC diagnosed via FOB and IDA } \\
\text { pathways show significant differences in the proportion } \\
\text { with right-sided cancer (31\% } \mathrm{V} \% \text {, P<0.001) and } \\
\text { anaemia (20\% v 98\%, P<0.001). This might imply that } \\
\text { they identify distinct CRC sub-populations. }\end{array}$ \\
\hline $\begin{array}{l}\text { How might it impact on } \\
\text { clinical practice in the } \\
\text { foreseeable future? }\end{array}$ & $\begin{array}{l}\text { The findings have theoretical implications for the } \\
\text { is support for the concept that systematic monitoring of } \\
\text { at-risk populations for IDA may complement the current } \\
\text { bowel cancer screening programme. }\end{array}$ \\
\hline
\end{tabular}


Keywords

Colorectal cancer

Bowel cancer screening programme

Iron deficiency anaemia

Abbreviations

CRC

Colorectal cancer

IDA

Iron deficiency anaemia

$\mathrm{Hb}$

Blood haemoglobin concentration

BCSP

Bowel Cancer Screening Programme

FOB

Faecal occult blood

gFOBt

Guaiac-based faecal occult blood testing

FIT

Faecal immunochemical testing 


\section{Introduction}

Colorectal cancer (CRC) is the fourth commonest cancer in the United Kingdom, accounting for $12 \%$ of all new cases; and the second commonest cause of cancer-related death, responsible for about $10 \%$ of events 12 . Although the mortality from CRC is slowly falling, the 5-year survival rate for $\mathrm{CRC}$ is still relatively poor at $58 \%{ }^{34}$.

Because CRC may not cause symptoms until the disease is already advanced, the focus over recent years has been on early diagnosis by screening of the pre-symptomatic at-risk population ${ }^{15}$. The English Bowel Cancer Screening Programme (BCSP) was developed with the aim of reducing the mortality rate ${ }^{5}$. Guaiac-based faecal occult blood testing (gFOBt) was introduced in 2006 (and switched to the faecal immunochemical test (FIT) in 2019), the aim being to detect in stool samples the presence of small quantities of blood derived from the tumour bed. Bowel cancer screening by gFOBt has been shown to reduce the mortality rate of CRC by about $15 \%$, primarily because cases are detected at an earlier stage ${ }^{6-8}$.

The second major pathway for pre-symptomatic diagnosis of CRC is through the detection of iron deficiency anaemia (IDA) ${ }^{9-14}$, believed to be due to chronic low-grade loss of (iron-rich) blood from the tumour bed, resulting in the slowly progressive depletion of iron stores. As IDA often occurs before any other clinical manifestations of $C R C^{13}{ }^{14}$, and may precede the diagnosis of $\mathrm{CRC}$ by up to 2 years ${ }^{15}$, detection of it can also provide an opportunity to diagnose $\mathrm{CRC}$ earlier in the disease course. This is the major rationale for the investigation of unexplained IDA in the at-risk population on an urgent basis 1617 .

It could be argued that FOB positivity and IDA are two sides of the same coin, both being manifestations of chronic blood loss from the CRC tumour bed. It 
might therefore be predicted that these two approaches to the early diagnosis of CRC might identify broadly similar CRC sub-populations. The aim of this study was to assess whether this is in fact the case, by comparing the clinical characteristics of patients with CRC diagnosed via BCSP and IDA pathways, based on the analysis of a large single centre database.

\section{Method}

We undertook statistical analysis of anonymised clinical data for all 1258 cases on the Poole Hospital CRC MDT database for the years 2010 to 2016 inclusive. The data was assessed in 2018 for the purposes of a service audit and included:

- age at diagnosis

- sex

- haemoglobin concentration $(\mathrm{Hb})$ at presentation - anaemia was defined as an $\mathrm{Hb}$ below the lower limit of normal for the local laboratory (130 g/l for males, $115 \mathrm{~g} / \mathrm{l}$ for females)

- tumour number, histology and location(s)

- presentation pathway - (1) symptomatic, (2) BCSP or (3) IDA

For the purposes of this study, CRCs located at or distal to the splenic flexure were considered left-sided, whilst those proximal to splenic flexure were labelled right-sided. Cases with synchronous tumours were considered rightsided if any tumour was proximal to the splenic flexure.

All subjects in the IDA group had the diagnosis confirmed by haematinics according to standard criteria ${ }^{14}{ }^{16}$. Most in this group were channelled through an IDA Clinic with a protocol for ensuring this ${ }^{13}$. 
The "symptomatic" presentation group comprised cases with symptoms relating directly to the underlying $\mathrm{CRC}$ (other than symptomatic anaemia) that resulted in GP referral or emergency admission to secondary care. Patients with both bowel symptoms and IDA were allocated to a presentation pathway based on which was felt to be the dominant feature - in a few cases this was rather arbitrary, but the allocation was made without knowledge of tumour site or stage.

About $11 \%$ of cases were removed from the database after applying exclusion criteria (listed in Table 1). The commonest reason for exclusion due to incomplete data was the absence of a blood count result in the patient record. Of the cases remaining, $90 \%$ had histologically confirmed colorectal adenocarcinoma, and most of the others had high-grade dysplasia on biopsy, undifferentiated carcinoma, or signet cell carcinoma. In the small minority without histological confirmation, cases were included only if the radiological features were regarded as characteristic of CRC, and they were managed as such clinically.

Pearson's Chi-squared test was used to compare sex ratio, side proportions, and anaemia proportions in the IDA and BCSP groups. The Mann-Whitney test was used to compare age and $\mathrm{Hb}$ in IDA and BCSP groups. The significance level was set to 0.05. R (version 3.6.1) and RStudio (version 1.2.5001) were used to run the statistical tests and to produce the descriptive statistics. 
Table 1 Exclusion criteria and numbers

\begin{tabular}{|l|l|}
\hline Incomplete dataset & 34 \\
\hline Second entry due to metachronous CRC & 7 \\
\hline $\begin{array}{l}\text { Other neoplasm eg neuroendocrine tumour, anal } \\
\text { carcinoma }\end{array}$ & 35 \\
\hline Non-incident presentation, CRC diagnosed elsewhere & 27 \\
\hline $\begin{array}{l}\text { CRC diagnosed on cancer follow-up or incidental } \\
\text { finding on scan }\end{array}$ & 34 \\
\hline
\end{tabular}

\section{Results}

After applying the exclusion criteria, 1121 cases were available for detailed analysis, and eight of these had synchronous CRCs. Just under $70 \%$ of cases presented via the symptomatic pathway, with about $15 \%$ each through the BCSP and IDA routes (Table 2).

There was a major difference between the BCSP and IDA groups in the proportion of cases with anaemia at diagnosis (Table 2). The prevalence of anaemia in the IDA group was of course high by definition - the figure was $98.2 \%$ rather than $100 \%$ because a small number of cases with confirmed iron deficiency were not anaemic by laboratory criteria. In contrast, only a small minority of the BCSP group were anaemic, despite being FOB positive by definition - the figure was $20 \%$, compared to $46.6 \%$ for the symptomatic group and $98.2 \%$ for the IDA group (Figure 1). 
The other major difference between the BCSP and IDA groups was in the location of the CRCs identified. Whilst 39\% presented with right-sided tumours overall, the proportion was markedly higher in the IDA group. Right sided tumours accounted for $31.6 \%$ in the symptomatic group and $31.1 \%$ in the BCSP group, compared to $82.5 \%$ of the IDA group (Table 2).

To explore the possibility that tumour location might account for the observed difference in the prevalence of anaemia in the two groups, the percentage of cases meeting laboratory criteria for anaemia were broken down by presentation pathway and tumour location. Figure 1 shows that regardless of location, only a small minority of BCSP subjects were anaemic.

Table 2 also reveals differences between the BCSP and IDA groups in terms of the other variables assessed. Predictably, subjects with $\mathrm{CRC}$ presenting through the BCSP pathway were younger at diagnosis. There was a trend towards BCSP cancers being commoner in males than females, though this did not reach statistical significance. 
Table 2 Descriptive statistics of the CRC dataset according to presentation pathway (BCSP : Bowel Cancer Screening Programme; IDA : iron deficiency anaemia; $Q 1$ - Q3 : interquartile range; $\mathrm{Hb}$ : haemoglobin concentration at diagnosis)

\begin{tabular}{|c|c|c|c|c|c|}
\hline & & Symptomatic & BCSP & IDA & $\begin{array}{l}\text { P value } \\
\text { [BCSP v IDA] }\end{array}$ \\
\hline Number & $\begin{array}{l}\mathrm{n} \\
\text { (\% of cohort) }\end{array}$ & $\begin{array}{l}770 \\
(68.7 \%)\end{array}$ & $\begin{array}{l}180 \\
(16.1 \%)\end{array}$ & $\begin{array}{l}171 \\
(15.3 \%)\end{array}$ & - \\
\hline Sex ratio & $M / F$ & 1.3 & 1.4 & 1.1 & 0.34 \\
\hline $\begin{array}{l}\text { Age } \\
\text { (years) }\end{array}$ & $\begin{array}{l}\text { Median } \\
\text { (Q1-Q3) }\end{array}$ & $\begin{array}{l}75 \\
(64-82)\end{array}$ & $\begin{array}{l}68 \\
(64-71)\end{array}$ & $\begin{array}{l}78 \\
(71-86)\end{array}$ & $<0.001$ \\
\hline $\mathrm{Hb}(\mathrm{g} / \mathrm{l})$ & $\begin{array}{l}\text { Median } \\
\text { (Q1-Q3) }\end{array}$ & $\begin{array}{l}124 \\
(106-140)\end{array}$ & $\begin{array}{l}138 \\
(126-147)\end{array}$ & $\begin{array}{l}89 \\
(80-100)\end{array}$ & $<0.001$ \\
\hline Anaemic & $\begin{array}{l}\mathrm{n} \\
\text { (\% of group) }\end{array}$ & $\begin{array}{l}359 \\
(46.6 \%)\end{array}$ & $\begin{array}{l}180 \\
(20.0 \%)\end{array}$ & $\begin{array}{l}168 \\
(98.2 \%)\end{array}$ & $<0.001$ \\
\hline $\begin{array}{l}\text { Right- } \\
\text { sided }\end{array}$ & $\begin{array}{l}\mathrm{n} \\
\text { (\% of group) }\end{array}$ & $\begin{array}{l}243 \\
(31.6 \%)\end{array}$ & $\begin{array}{l}56 \\
(31.1 \%)\end{array}$ & $\begin{array}{l}141 \\
(82.5 \%)\end{array}$ & $<0.001$ \\
\hline
\end{tabular}


Figure 1 The percentage of cases with anaemia at the time of diagnosis, subdivided by presentation pathway and tumour location. See text for definitions

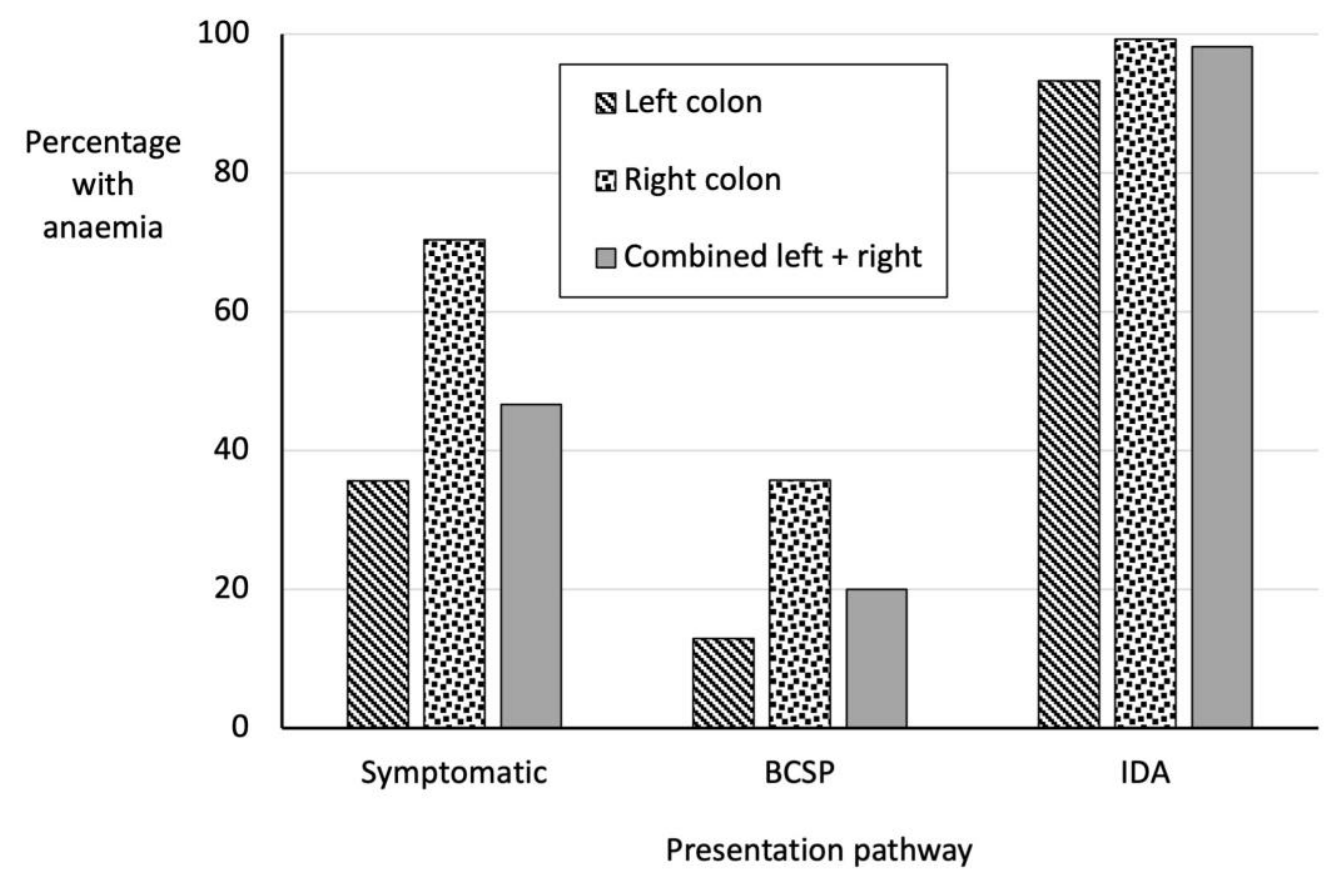




\section{Discussion}

The first key observation reported here is that whilst anaemia is commonly associated with CRC, most cases presenting via the BCSP pathway are not anaemic - despite being FOB positive by definition. The literature suggests that conversely, the sensitivity of occult blood positivity for IDA-related CRC is limited. Several large case-series of FIT in the assessment of bowel-related indications have revealed that $10-15 \%$ of $C R C$ s identified on investigation had a quantitative FIT $<10 \mathrm{ug} / \mathrm{g}$, and the dominant indication in this sub-group was IDA ${ }^{18-20}$. In keeping with this, a limited meta-analysis suggests that gFOBt and FIT both have a sensitivity of 0.83 for CRC in IDA populations possibly over-estimated through reporting bias ${ }^{21}$.

The second key observation is that CRC diagnosed through the IDA pathway appears to be quite distinct from that identified via the BCSP pathway - with a striking predominance of right-sided tumours, confirming previous observations ${ }^{9-14}$. BCSP cancers were more commonly diagnosed in males, and although this didn't reach statistical significance, it may be a relevant observation as men are less likely to take up the screening ${ }^{8}$. Subjects with CRC presenting through the BCSP were also younger, probably reflecting selection by the age-groups to which screening is offered 58 .

In summary, the prevalence of anaemia in BCSP-detected tumours is paradoxically low, the prevalence of occult blood positivity in IDA-related tumours is limited, and there are major phenotypic differences between CRCs and subjects identified by the two pathways. This disconnect challenges the assumption that occult blood positivity and iron deficiency are simply parallel manifestations of chronic blood loss from the tumour bed in CRC, and has both theoretical and practical implications. 
The observations require a pathophysiological explanation. Tumour location may be relevant, as the yield of occult blood testing ${ }^{22}$ and faecal haemoglobin concentrations on quantitative FIT ${ }^{18}$ both appear to be lower for right-sided CRCs. It is unclear whether this reflects differences in tumour biology, or the partial degeneration of haemoglobin to non-immunoreactive forms during passage through the colon from right-sided lesions. The persistence of differences in the prevalence of anaemia when controlling for the side of the lesion shown in the current study implies that laterality is not the whole explanation - although it may be a contributory factor.

As the development of IDA is gradual prior to the diagnosis of CRC ${ }^{15}$, an alternative explanation might be that BCSP tumours are picked up at an earlier stage than IDA cancers, so that although they are bleeding there has not been time to deplete body iron stores. However, whilst IDA-related CRC was historically notorious for presenting late, this may no longer be true ${ }^{23}$.

Finally, differences in tumour biology between the right and left colon 24-30 might be relevant. One area of interest is hepcidin, a key inhibitor of dietary iron absorption ${ }^{31}{ }^{32}$. Functionally significant tumour release of hepcidin has been described ${ }^{33}$, and limited studies to date have revealed increased hepcidin expression in $34-66 \%$ of colorectal cancers ${ }^{34}{ }^{35}$. It is not known whether this correlates with tumour location in the colon, or influences iron balance.

The strength of this study is the population size and homogeneity, whilst limitations include the uncertain applicability of a single centre experience. Anaemia was used as a surrogate marker of iron deficiency because the results of iron studies were not universally available, but we feel that this was reasonable as iron deficiency is the dominant mechanism of anaemia in CRC 1914. Finally, the BCSP group was screened using gFOBt, as the timeframe was prior to the change-over to FIT - although the sensitivity of gFOBt and FIT for IDA-related CRC appears to be similar ${ }^{21}$. 
The practical implication of our findings is that as BCSP and IDA pathways appear to identify different CRC sub-populations, there is a case for introducing systematic blood count monitoring to complement the BCSP ${ }^{23}$. The premise is that IDA screening would predominantly detect right-sided CRC, whilst the BCSP primarily targets left-sided CRC, and may be less effective for right-sided lesions ${ }^{78}$. 


\section{Acknowledgements}

Author contributions: OA, SDP and JS conceived and designed this study. OA analysed the data and drafted the manuscript. All authors made significant contributions to the subsequent revision of the paper and approved the final version. The authors would like to thank Professor Peter Thomas for his contribution to this study.

Funding sources: PhD studentship (OA) jointly funded by Poole Hospital Gastroenterology Research fund and Bournemouth University.

Competing interests: None.

Data Sharing Statement: Data available on reasonable request.

Ethics approval: retrospective analysis of anonymised data, formal Research Ethics approval was not required.

Patient consent for publication: not required. 


\section{References}

1. Dekker E, Tanis PJ, Vleugels JLA, et al. Colorectal Cancer. Lancet 2019;19:1467-80

2. Cancer Research UK. Bowel Cancer Incidence Statistics. 2017. https://www.cancerresearchuk.org/health-professional/cancerstatistics/statistics-by-cancer-type/bowel-cancer\#heading-Zero [Accessed 2 Oct 2020]

3. Cancer Research UK. Bowel Cancer Survival Statistics. 2017. https://www.cancerresearchuk.org/health-professional/cancerstatistics/statistics-by-cancer-type/bowel-cancer\#heading-Two. [Accessed 2 Oct 2020]

4. Cancer Research UK. Bowel Cancer Survival by Stage at Diagnosis. 2018. https://www.cancerresearchuk.org/health-professional/cancerstatistics/statistics-by-cancer-type/bowel-cancer/survival\#heading-Three. [Accessed 2 Oct 2020]

5. Public Health England. Bowel Cancer Screening Programme (BCSP): Overview. 2019. https://www.gov.uk/guidance/bowel-cancer-screeningprogramme-overview. [Accessed 8 Nov 2020]

6. Towler B, Irwig L, Glasziou P, et al. A Systematic Review of The Effects of Screening For Colorectal Cancer Using The Faecal Occult Blood Test, Hemoccult. BMJ 1998;317:559-65

7. Hardcastle JD, Chamberlain JO, Robinson $\mathrm{MH}$, et al. Randomised Controlled Trial of Faecal-Occult-Blood Screening For Colorectal Cancer. Lancet 1996;348:1472-77

8. Logan RF, Patnick J, Nickerson C, et al. Outcomes of the Bowel Cancer Screening Programme (BCSP) in England after the first 1 million tests. Gut 2012;61:1439-46

9. Beale A, Penney M, Allison M. The Prevalence of Iron Deficiency Among Patients Presenting With Colorectal Cancer. Colorectal Disease 2005;7:398-402 
10. Edna TH, Karlsen V, Jullumstrø $E$ et al. Prevalence of Anaemia At Diagnosis of Colorectal Cancer: Assessment of Associated Risk Factors. Hepatogastroenterology 2012;59:713-16

11. Ho CH, Yu YB, Wu PH. The Prevalence of Iron Deficiency Anemia And Its Clinical Implications In Patients With Colorectal Carcinoma. Journal of the Chinese Medical Association 2008;71:119-22

12. Alexiusdottir KK, Möller PH, Snaebjornsson P, et al. Association of Symptoms of Colon Cancer Patients With Tumor Location And Tnm Tumor Stage. Scandinavian Journal of Gastroenterology 2012;47:795-01

13. Stone H, Almilaji O, John C, et al. The Dedicated Iron Deficiency Anaemia Clinic: a 15-Year Experience. Frontline Gastroenterology 2020 https://doi.org/10.1136/flgastro-2020-101470

14. Pasricha SR, Tye-Din J, Muckenthaler MU, Swinkels DW. Iron deficiency. Lancet. 2021 Jan 16;397(10270):233-248. doi: 10.1016/S01406736(20)32594-0

15. Edgren G, Bagnardi V, Bellocco R et al. Pattern of Declining Hemoglobin Concentration Before Cancer Diagnosis. International Journal of Cancer 2010;127:1429-36

16. Goddard A, James M, Mclntyre A, et al. Guidelines For The Management of Iron Deficiency Anaemia. Gut 2011;60:1309-1316

17. National Institute for Health And Care Excellence (NICE). Suspected Cancer: Recognition and Referral. 2015, updated Sep 2020. https://www.nice.org.uk/guidance/ng12 [Accessed 8 Nov 2020]

18. Chapman C, Bunce J, Oliver $S$ et al. Service evaluation of faecal immunochemical testing and anaemia for risk stratification in the 2-weekwait pathway for colorectal cancer. BJS Open 2019;3(3):395-402. doi: 10.1002/bjs5.50131

19. Mowat C, Digby J, Strachan JA et al. Impact of introducing a faecal immunochemical test (FIT) for haemoglobin into primary care on the outcome of patients with new bowel symptoms: a prospective cohort 
study. BMJ Open Gastroenterol. 2019;6(1):e000293. doi: 10.1136/bmjgast-2019-000293

20. Cunin L, Khan AA, Ibrahim M, Lango A, Klimovskij M, Harshen R. FIT negative cancers: A right-sided problem? Implications for screening and whether iron deficiency anaemia has a role to play. Surgeon 2021;19(1):27-32. doi: 10.1016/j.surge.2020.02.003

21. Lee MW, Pourmorady JS, Laine L. Use of Fecal Occult Blood Testing as a Diagnostic Tool for Clinical Indications: A Systematic Review and MetaAnalysis. Am J Gastroenterol. 2020;115(5):662-670. doi: 10.14309/ajg.0000000000000495

22. Chiu HM, Lee YC, Tu CH et al. Association between early-stage colon neoplasms and false-negative results from the fecal immunochemical test. Clin Gastroenterol Hepatol. 2013;11(7):832-8.e1-2. doi: 10.1016/j.cgh.2013.01.013

23. Almilaji O, Parry SD, Docherty S, Snook JA. Evidence for improved prognosis of colorectal cancer diagnosed following the detection of iron deficiency anaemia Nature Scientific Reports 2021;11:13055 https://doi.org/10.1038/s41598-021-92623-z

24. Nawa T, Kato J, Kawamoto H, et al. Differences Between Right And LeftSided Colon Cancer In Patient Characteristics, Cancer Morphology And Histology. Journal of Gastroenterology and Hepatology 2008;23:418-23

25. Hansen I, Jess P. Possible Better Long-Term Survival In Left Versus Right-Sided Colon Cancer - A Systematic Review. Danish Medical Journal 2012;59:A4444

26. Snaebjornsson $P$, Jonasson $L$, Jonsson $L$ et al. Colon Cancer In Iceland: A Nationwide Comparative Study on Various Pathology Parameters With Respect To Right And Left Tumor Location And Patients Age. International Journal of Cancer 2010;127:2645-53

27. Petrelli F, Tomasello G, Borgonovo $\mathrm{K}$ et al. Prognostic Survival Associated With Left-Sided Vs Right-Sided Colon Cancer: A Systematic Review And Meta-Analysis. JAMA Oncology 2017;3:211-19 
28. Yahagi M, Okabayashi $\mathrm{K}$, Hasegawa $\mathrm{H}$ et al. The Worse Prognosis of Right-Sided Compared with Left-Sided Colon Cancers: A Systematic Review and Meta-Analysis. Gastrointestinal Surgery 2016;20:648-55

29. Mik M, Berut M, Dziki L et al. Right And Left-Sided Colon Cancer Clinical And Pathological Differences of The Disease Entity In One Organ. Archives of Medical Science 2017;13:157-162

30. Ghazi S, Lindforss $U$, Lindberg $G$ et al. Analysis of Colorectal Cancer Morphology In Relation To Sex, Age, Location, And Family History. Journal of Gastroenterology 2012;47:619-34

31. Vela D, Vela-Gaxha Z. Differential regulation of hepcidin in cancer and non-cancer tissues and its clinical implications. Exp Mol Med. 2018;50(2):e436. doi: 10.1038/emm.2017.273

32. Nemeth E, Ganz T. The role of hepcidin in iron metabolism. Acta Haematol. 2009;122(2-3):78-86. doi: 10.1159/000243791

33. Weinstein DA, Roy CN, Fleming MD, Loda MF, Wolfsdorf JI, Andrews NC. Inappropriate expression of hepcidin is associated with iron refractory anemia: implications for the anemia of chronic disease. Blood. 2002;100(10):3776-81. doi: 10.1182/blood-2002-04-1260

34. Ward DG, Roberts K, Brookes MJ et al. Increased hepcidin expression in colorectal carcinogenesis. World J Gastroenterol. 2008;14(9):1339-1345. doi:10.3748/wjg.14.1339

35. Xiang-tao P. Expression of Hepcidin and Neogenin in colorectal cancer. Open Medicine 2017;12(1):184-188 https://doi.org/10.1515/med2017-0027 